\title{
The Potential of Rural Tourism Development in the Azores Islands from the Perspective of Public Administration and Decision-Makers
}

\author{
GUALTER COUTO \\ School of Business and Economics and CEEAplA \\ University of Azores \\ 9500-321 Ponta Delgada, Portugal \\ PORTUGAL \\ PEDRO PIMENTEL \\ School of Business and Economics and CEEAplA \\ University of Azores \\ 9500-321 Ponta Delgada, Portugal \\ PORTUGAL \\ MARIA DA GRAÇA BATISTA \\ School of Business and Economics and CEEAplA \\ University of Azores \\ 9500-321 Ponta Delgada, Portugal \\ PORTUGAL \\ ÁUREA SOUSA \\ Faculty of Sciences and Technologies and CEEAplA \\ University of Azores \\ 9500-321 Ponta Delgada, Portugal \\ PORTUGAL \\ CÉLIA CARVALHO
}

Faculty of Social and Human Sciences, University of Azores and CINEICC - Cognitive and

Behavioral Centre for Research and Intervention

University of Azores

9500-321 Ponta Delgada

PORTUGAL

Faculty of Psychology and Educational Sciences, University of Coimbra

University of Coimbra

3000-115 Coimbra

PORTUGAL

RUI ALEXANDRE CASTANHO

Faculty of Applied Sciences, WSB University

41-300 Dabrowa Górnicza

POLAND

Abstract: Regional planning policies are an essential instrument for allowing the local inhabitants' necessary life
quality standards. Those planning tools support future living prosperity in that territory, encouraging the ending
of spatial and social inequalities as an incentive instrument for the so-desired sustainable development.
Thereby, this paper aims to analyze the Public Administration and Decision-Makers' opinions concerning the
Potential of Rrural Tourism Development in the Azores Islands. We used an exploratory methodology, which 
enabled to assess those perceptions. Consequently, it was possible to understand that the public administration's role in fostering and coordinating rural tourism is pivotal for this activity's continued sustained growth. Besides, throughout this study, it was possible to understand that regional development has been decisive and has decidedly influenced the local population. The research also recognizes that are many advantages in this typology of tourism for local communities - i.e., job creation or stimulating the local economy, are just a few examples.

\section{Keywords: Azores Islands; Public Administration; Sustainable Development; Sustainable Tourism; Territorial} Governance and Management.

Received: December 22, 2020. Revised: June 14, 2021. Accepted: July 1, 2021. Published: July 8, 2021.

\section{Introduction}

Rural and nature-based tourism can sum substantially to the sustainable development and growth of lowdensity areas or rural areas [1-8].

Consequently, it should be emphasized that these regions hold numerous difficulties associated with economic decay, a substantial rise in unemployment, populational exodus as emigration, unfavorable consequences of restructuring agriculture, or the decline of cultural identity, are just a few examples [8-13].

Besides, several scholars state that entrepreneurship, associated with small and medium-sized businesses, is one way to achieve sustainable development in peripheral regions like the Southern European countries - once it permits improving employment and incoming [2-4,11-15]. Moreover, the preliminary results of an investigation that addressed the difference of entrepreneurship between regions of distinct sizes revealed that outside and local access to the Gross Regional Product (or accessibility to markets) has a meaningful influence on an innovative company's entry and exit [13].

In fact, this result is damaging the primary and secondary sectors, while this impact is positive for the services sector [13].

Thereby, this typology of tourism is an activity that can be a catalyst for the territories towards sustainable development. So, it should be highly considered by the main actors and decision-makers.

Thus, and considering the specific features presented by the Azores Islands' ultra-peripheral territory, this paper aims to understand the perceptions of the Public Administration and Decision-Makers about the potential of rural tourism development in the Azores Archipelago.

Accordingly, it is foreseen that this investigation fulfills a significant gap in thematic literature. In this regard, the authors used exploratory tools about the Azores Public Administration and Decision-Makers' perceptions of the potential of rural tourism development in the Azores Islands.

\section{Regional Development and Rural Tourism: A Short Framework}

If we look to the UNWTO (United Nations World Tourism Organisation) [16] definition of tourism, we found that is "(...) the activities of persons traveling and staying in places outside their usual environment for not more than one consecutive year for leisure, business, and other purposes." Therefore, based on this description, three components should be introduced: (i) transportation outside, (ii) reason for traveling, and (iii) the maximum number of days stayed [17]. In this regard, tourism development improves tourism facilities or activities to attract visitors, including the sustainability of these activities to benefit tourists, community members, and tourism. Thus, the resilience of a tourism destination should be advanced [18].

The above mentioned are just a few examples of several other tourism typologies, which are more connected with rural tourism activity. Accordingly, considering this study field, agritourism, ecotourism, nature-based tourism, or wine tourism deserve a closer look. Contextually, agritourism can be defined as an activity, which inspires travelers to visit farms [19]. Various forms of agritourism exist, especially farm, farm-based and rural tourism [20]. Here, Sonnino [21] describes an agricultural producer's and their family's hospitality actions that connect to any form of farming. In this sense, Barbieri and Mshenga [22] recognized agritourism as the operation generated to draw visitors to an operative farm. In some cases, these visitors are from urban areas rather than rural areas where the farm is located [18]. Most of these individuals farm as substance farming. Thus, it is excluded commercial farming, which is on a broader scale. Examples of agritourism include wine tourism, farmers' markets, or fruit picking - among several other examples. 
Ecotourism intends to produce knowledge, generate capital for conservation, improve the attention of cultures, and provide better regional communities, economic inclusion, and political influence [22-25]. This type of tourism induces tourists to a region that includes the fauna, flora, and culture. Here, we also have geotourism, a tourism type that recognizes the physical environment cultivating conservation through education and other procedures - i.e. geo-trails, protected area visits, or guided tours, among many others [26-28].

Wine tourism encompasses more than simply the consumption of wine [18]. Scholars as Mitchell and Li [24] differentiated among primary wine tourism for wine tasting and procurement, secondary or 'peripheral' wine tourism motivations - i.e., festivals or gastronomy. Moreover, wine consumption near the area where the wine was made is known as wine tourism or enotourism [18].

\section{Methodology}

In order to perform this research objective, multiple procedures and methods were used, as direct and indirect analysis methods. Thereby, the methodological structure was divided into four primary levels:

(i) interviews design;

(ii) data collection;

(iii) case study analysis;

(iv) results interpretation and, discussion and conclusions.

The last level gathers on Public Administration and Decision-Makers' thoughts about the potential of rural tourism development in the Azores Islands. Therefore, it was reasonable to suggest some guidelines and recommendations for regional tourism planning.

\subsection{Design and Implementation of the Interviews}

The interview was created, recognizing the need for an online modality. More specifically, we conducted a web interview using Google Forms. Even if we know that online interviews are susceptible to inclinations in the results of an empirical study, this typology of the interview was chosen due to social distancing in the actual pandemic crisis scenario conditions.

More than forty participants formed the sample group. The group was formed by the Azores Public
Administration and Decision-Makers, which are the most suitable participants for this study typology. Also, the web interviews were conducted between May and December of 2020. The sample group data are shown in Table 1.

Table 1: Sample group data.

\begin{tabular}{|c|c|c|}
\hline & Variables & $\%$ \\
\hline \multicolumn{3}{|c|}{ Gender } \\
\hline \multirow{3}{*}{ Valid } & Female & 44,4 \\
\hline & Male & 55,6 \\
\hline & Total & $100,0 \%$ \\
\hline & Variables & $\%$ \\
\hline \multicolumn{3}{|c|}{ Age Group } \\
\hline \multirow{4}{*}{ Valid } & $18-35$ & $37,8 \%$ \\
\hline & $36-50$ & $44,4 \%$ \\
\hline & $51-65$ & $17,8 \%$ \\
\hline & Total & $100,0 \%$ \\
\hline
\end{tabular}

Considering the study scope, the authors selected concise and direct questions about the potential of rural tourism development perceptions in the Azores Archipelago.

After data collection, the authors used the Statistical Package for the Social Sciences (SPSS) for data analysis since it was possible to extract the most straightforward direct answers from the data.

\section{Study Results}

Two closed-up questions (Table 2 and, Table 3) were conducted to evaluate the respondents' rural tourism experiences. More than fifty percent of the Decisionmakers and Public Administrators claimed that they had previously had some rural tourism experience in the Azores Islands. Also, most of those who had a rural tourism experience in the Azores Islands state that this experience was "Very Good" (Table 2).

Table 2: Closed-up question about rural tourism experience in the Azores.

\begin{tabular}{|c|c|c|c|}
\hline \multicolumn{4}{|c|}{$\begin{array}{l}\text { Question a: Have you ever had a Rural Tourism } \\
\text { experience in the Azores? }\end{array}$} \\
\hline & & Frequency & $\%$ \\
\hline \multirow{3}{*}{ Valid } & Yes & 25 & $\overline{55,6}$ \\
\hline & No & 19 & 42,2 \\
\hline & Total & 44 & 97,8 \\
\hline Missing & $\begin{array}{c}\text { Do not } \\
\text { know / Do } \\
\text { not answer }\end{array}$ & 1 & 2,2 \\
\hline \multicolumn{4}{|c|}{$\begin{array}{l}\text { Question a.i: If you answered yes to the previous } \\
\text { question, how would you rate it? }\end{array}$} \\
\hline & & Frequency & $\%$ \\
\hline \multirow{3}{*}{ Valid } & Excellent & 5 & 11,1 \\
\hline & Very Good & 15 & 33,3 \\
\hline & Good & 4 & 8,9 \\
\hline
\end{tabular}




\begin{tabular}{|l|c|c|c|}
\hline & Satisfactory & 1 & 2,2 \\
\cline { 2 - 4 } & Total & 25 & 55,6 \\
\hline Missing & - & 20 & 44,4 \\
\hline
\end{tabular}

In Table 3, it is conceivable to recognize that the majority of the respondents consider that rural tourism has improved in the Azores Islands' in the last decade (more than 80\%). Moreover, the participants also believe that regional development has been positive and has positively influenced the local population $(88,9 \%)$.

Table 3: Closed-up question about how rural tourism has increased in the Azores Islands'.

Question b: Do you believe that rural tourism has increased in the Azores Islands' in the last decade from a comparative perspective?

\begin{tabular}{|c|c|c|c|}
\multicolumn{4}{|c|}{ from a comparative perspective? } \\
\hline \multirow{3}{*}{ Valid } & Yes & 37 & Prequency \\
\cline { 2 - 4 } & No & 4 & 82,2 \\
\cline { 2 - 4 } & Total & 41 & 8,9 \\
\hline \multirow{2}{*}{$\begin{array}{c}\text { Missi } \\
\text { ng }\end{array}$} & $\begin{array}{c}\text { Do not } \\
\text { know / } \\
\text { Do not } \\
\text { answer }\end{array}$ & 4 & 91,1 \\
\hline
\end{tabular}

Question b.i: From a comparative perspective, with the last decade, do you believe that regional development was positive and created positive impacts on the local population?

\begin{tabular}{|c|c|c|c|}
\hline & & Frequency & Percent \\
\hline \multirow{3}{*}{ Valid } & Yes & 40 & 88,9 \\
\cline { 2 - 4 } & No & 1 & 2,2 \\
\cline { 2 - 4 } & Total & 41 & 91,1 \\
\hline \multirow{2}{*}{$\begin{array}{c}\text { Do not } \\
\text { know / } \\
\text { Do not } \\
\text { answer }\end{array}$} & 4 & 8,9 \\
\hline
\end{tabular}

Furthermore, applying a Categorical Principal Component Analysis, with Varimax rotation and Kaiser Normalization to a set of 29 items on a scale of 1 (totally disagree) to 5 (totally agree), seven principal components (dimensions) were extracted. The percentage of variance accounted for (PVAF) across these components is $79,517 \%$ of the data's total variance. So, Table 4 shows the loadings regarding each element after the rotation analysis and the Cronbach's alpha coefficient, the eigenvalues, and the percentage of variance explained by each component. All components (dimensions) have eigenvalues greater than unity. Moreover, six principal components have satisfactory internal consistency, while the seventh component has an acceptable inner surface.

The items A20, A21, A17, A12, A11, A18 and A8, are associated with the first component designated "Role of public administration in fostering and coordinating rural tourism."

Items A26, A3 and A28 are the most critical items for the second component. Thereby, this component was named "Impacts of Rural Tourism on regional development."

Items A16, A5, A7, A15, A6 and A19 are correlated with the third component, that was called "Incentives for Rural Tourism."

Items A23, A22, A24, A25 and A2 are the most critical items for the fourth component, and consequently, this component was named "Marketing, quality, and adequacy of infrastructure to Rural Tourism."

The fifth component exhibits the strongest correlations with items A9, A10 and A4, and for this reason, this component can be called "Promotion of rural tourism in a sustainable manner."

Items A14, A13 and A1 are associated with the sixth component, was entitled "Interaction between Public Administration and the community."

The items A27 and A29 are the most relevant items for the seventh component; therefore, this component was called "Training of human resources in the area of Rural Tourism and telephone network coverage in the region."

Thus, the application of the CatPCA made it possible to reduce the dimensionality of the data and identify four critical factors within the scope of a bet on the development of Rural Tourism.

Table 4: Rotated component loadings of the 7component solution.

\begin{tabular}{|l|c|c|c|c|c|c|c|}
\hline \multirow{2}{*}{ Items } & \multicolumn{7}{|c|}{ Component* } \\
\cline { 2 - 8 } & 1 & 2 & 3 & 4 & 5 & 6 & 7 \\
\hline $\begin{array}{l}\text { A20 There is } \\
\text { good } \\
\text { communication }\end{array}$ & .987 & & & & & & \\
\hline
\end{tabular}




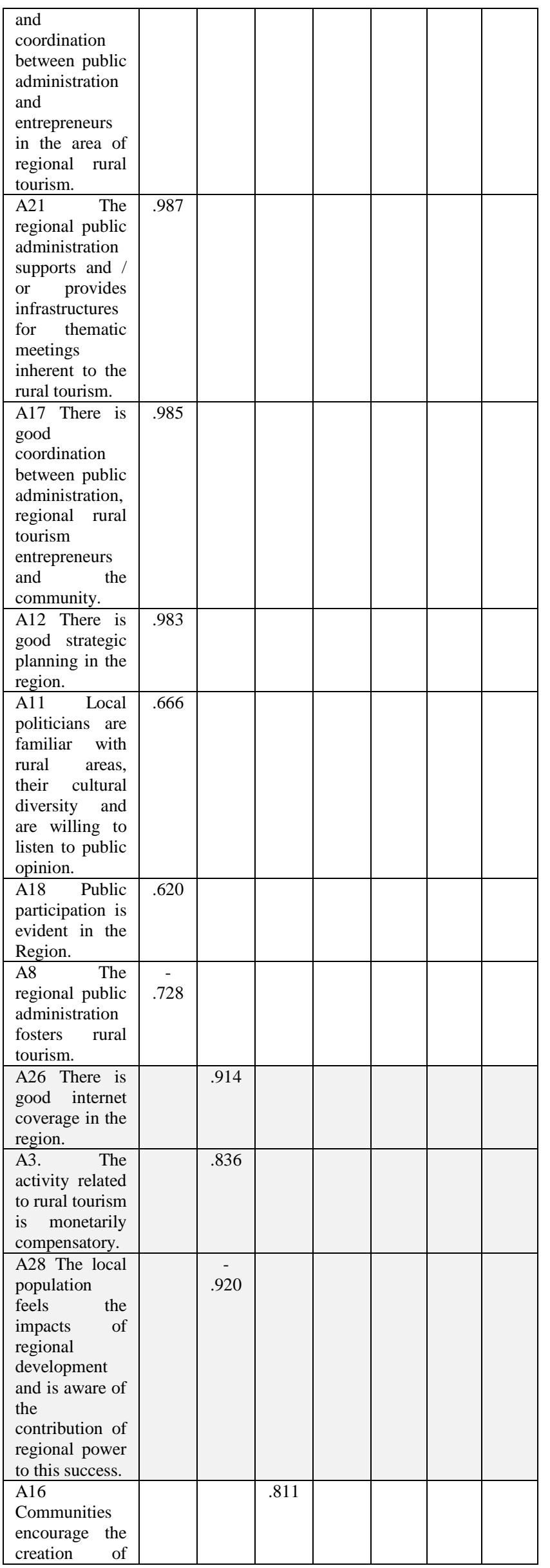

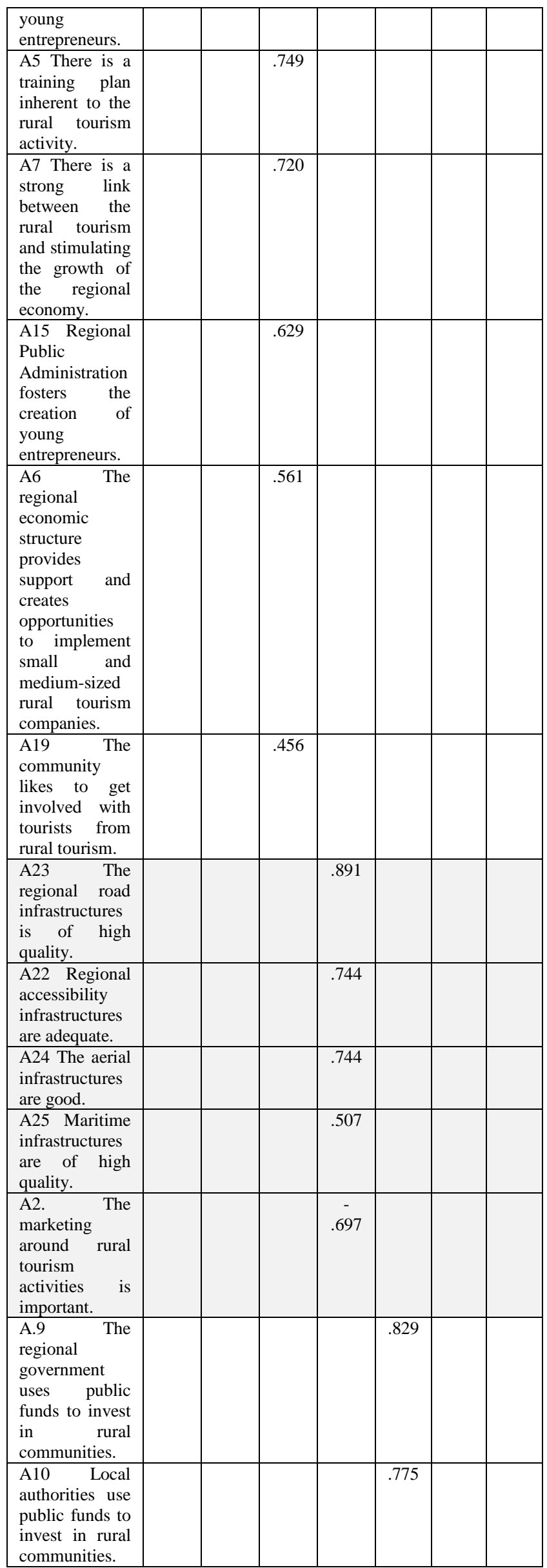




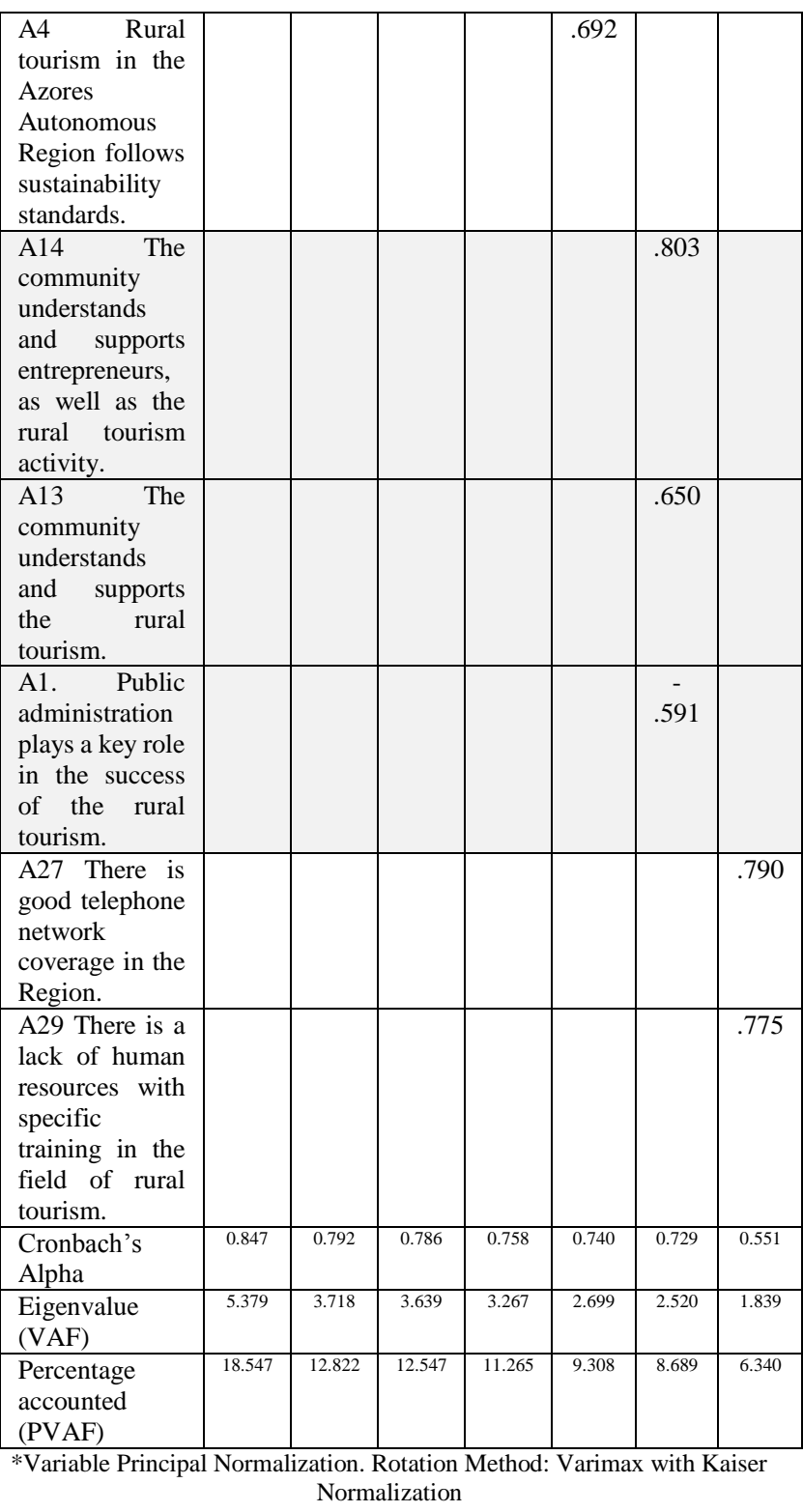

Besides, and based on the decisive factors identified by Castanho et al. [14,15] for regional success in peripheral territories, the participants were asked to discuss their relevance to each of those factors for the success of the ultra-peripheral region of the Azores (Table 5). Concerning the Azores' Rural Tourism activity's success, the decision-makers and public administration attribute greater weight to the following factors: "Protection and conservation of Nature" and "Greater commitment and political transparency."

Table 5: The pivotal factors for the success of the ultra-peripheral territory of the Azores, in the opinion of the participants.

\begin{tabular}{|l|c|c|}
\hline $\begin{array}{c}\text { Factors for the Success of Rural } \\
\text { Tourism in the Azores Region }\end{array}$ & Mode & P75 \\
\hline $\begin{array}{l}\text { i. Connectivity - Movement and } \\
\text { displacements (between urban centers, } \\
\text { islands, etc.) }\end{array}$ & 3 & 4 \\
\hline
\end{tabular}

\begin{tabular}{|l|c|c|}
\hline $\begin{array}{l}\text { ii. Strengthening of the Regional } \\
\text { Territorial Strategy }\end{array}$ & 3 & 4 \\
\hline $\begin{array}{l}\text { iii. Avoid duplication of infrastructure in } \\
\text { the Region }\end{array}$ & 3 & 4 \\
\hline $\begin{array}{l}\text { iv. Sense of Belonging of the Residents } \\
\text { v. Offer Diversification }\end{array}$ & 3 & 3.5 \\
\hline vi. Ease of Access to Regional Funds & 3 & 4 \\
\hline vii Strengthening the Economy & 3 & 4 \\
\hline viii. Standards of life quality & 3 & 4 \\
\hline $\begin{array}{l}\text { ix. Magnet for Young and Talented } \\
\text { People }\end{array}$ & 3 & 4 \\
\hline $\begin{array}{l}\text { x. Definition of common objectives and } \\
\text { strategies } \\
\text { administration-entrepreneurs- } \\
\text { population) }\end{array}$ & 3 & 4 \\
\hline $\begin{array}{l}\text { xi. Greater political commitment and } \\
\text { transparency }\end{array}$ & 4 & 4 \\
\hline $\begin{array}{l}\text { xii. Protection and conservation of } \\
\text { Nature }\end{array}$ & 4 & 4 \\
\hline xiii. Public participation & 3 & 4 \\
\hline xiv. Marketing and advertisement & 3 & 4 \\
\hline$x v$. Other & 1 & 3 \\
\hline
\end{tabular}

\section{Discussion}

Public Administration in the Azores Islands still has a relevant role in the coordination of rural tourism development, still influences how regional tourism impacts regional development, and still influences the construction of infrastructures that allow this area to develop.

Despite all this influence, the community still is not aware of the impact of rural tourism in the development of the Azores and the influence of the regional government in this success. However, entrepreneurs consider the investment in rural tourism a satisfactory activity regarding the monetary return.

It is widely recognized that there is still a lack of training in human resources to comply with the needs and success of rural tourism, and, increasingly, rural communities support new activities related to rural tourism.

A positive point that is enhanced is that infrastructures (roads, aerial and maritime) allow good access to areas where rural tourism is implemented.

Curiously, marketing activities are not considered essential, probably because we deal with a particular market segment that uses singular disclosure channels.

Sustainability is, as globally considered, highly relevant to rural communities, rural tourism, and tourism in general. This fundamental subject is ruled by local authorities and the Azorean Government regarding medium and long-term investments and development plans. However, rural tourism success' is not considered an achievement of public administration but a symbiotic relation between rural communities and entrepreneurs that work together to 
develop the area and allow all participants to withdraw economic and social benefits from rural tourism activities.

\section{Conclusions}

In fact, this study is one of the first to investigate public administration and decision-makers opinions about the potential of rural tourism growth in the Azores Islands from an academic viewpoint. It is plausible to understand that the vast majority consider that rural tourism has increased in the Azores in the last ten years. Also, regional development has been decisive and has positively influenced the local residents.

If we look at the perception of the decision-makers and public administrators (the respondents), the main benefits of this type of tourism for the Region are: (i) job creation; (ii) the attraction of new tourists; (iii) the development of trade, services, and activities; and (iv) strengthening of the regional economy.

Besides, nature tourism, ecotourism, and adventure tourism, inspired by sustainability principles, can be decisive products in this model. These are pivotal ideas that underlie the regional plans and reemphasize the relevance of sustainability for constant development and valuation.

In this regard, the design of future regional plans that endeavor at sustainable development needs clearly to consider the factors identified in this research regarding the rural tourism development in the Azores Islands.

\section{Contribution of individual authors to the creation of a scientific article (ghostwriting policy)}

Author Contributions: All the authors contributed equally to the development of the present paper. All phases of the paper development have been proper discussed and worked on by the authors. All authors have read and agreed to the published version of the manuscript.

\section{Sources of funding for research presented in a scientific article or scientific article itself}

This paper is financed by Portuguese national funds through FCT-Fundação para a Ciência e a Tecnologia, I.P., project number UIDB/00685/2020 and by the project GREAT-Genuine Rural Experiences in the Azores Tourism, with the code: ACORES-01-0145-FEDER-000089.

\section{References:}

[1] Morais, J., Castanho, R., Pinto-Gomes, C., and Santos, P. (2018). Merging Traditional Livelihood Activities with New Employment Opportunities Brought by Ecotourism to Iona National Park, Angola: Rethinking Social Sustainability. Chapter in the Book: PLANEAMIENTO SECTORIAL: RECURSOS HÍDRICOS, ESPACIO RURAL Y FRONTERAS. Ed. Thomson Reuteurs Aranzadi. pp. 293-303 ISBN 978-84-1309-065-8.

[2] Loures L, and Panagopoulos T. (2010). Reclamation of derelict industrial land in Portugal greening is not enough. International Journal of Sustainable Development and Planning. 2010;5(4):343-350

[3] Santos, R., Castanho, R.A. and Lousada, S. (2019). Return Migration and Tourism Sustainability in Portugal: Extracting Opportunities for Sustainable Common Planning in Southern Europe. Sustainability 2019, $11, \quad 6468$; doi:10.3390/su11226468

[4] Santos, R., Castanho, R.A. and Lousada, S., (2020). The Portuguese Emigrants' Return and the Impacts over Tourism Development in Rural Areas: Directions for a Sustainable Planning. Chapter 5 (pp.85-100). in the Book: Espacios y Sociedades en Transformación. Ed. Thomson Reuters Aranzadi Spain. ISBN 978-84-1346-693-4

[5] Couto, G., Castanho, R.A., Sousa, A., Pimentel, P., Santos, C. and Carvalho, C., (2020). The Impacts of COVID-19 Crisis over the Tourism Expectations of the Azores Archipelago Residents. Sustainability 2020, 12, 7612; doi:10.3390/su12187612

[6] Couto G., Castanho R.A., Pimentel P., Carvalho C.B., Sousa Á. (2021). The Potential of Adventure Tourism in the Azores: Focusing on the Regional Strategic Planning. In: Abreu A., Liberato D., González E.A., Garcia Ojeda J.C. (eds) Advances in Tourism, Technology and Systems. ICOTTS 2020. 
Smart Innovation, Systems and Technologies, vol 209. Springer, Singapore. https://doi.org/10.1007/978-981-33-4260-6_2

[7] Ulucak R, Yücel AG, and İlkay SÇ. (2020) Dynamics of tourism demand in Turkey: Panel data analysis using gravity model. Tourism Economics. 2020;26(8):1394-1414. doi:10.1177/1354816620901956

[8] Cavaco, C. (2003). Habitares dos Espaços Rurais. Revista da Faculdade de Letras-Geografia. 1 série, XIX, pp. 47-64.

[9] Morais, J., Castanho, R.A., Loures, L., PintoGomes, C., and Santos, P. (2019). Villagers' Perceptions of Tourism Activities in Iona National Park: Locality as a Key Factor in Planning for Sustainability. Sustainability 2019, 11, 4448; doi:10.3390/su11164448

[10] Castanho, R.A. (2019). Identifying Processes of Smart Planning, Governance and Management in European Border Cities. Learning from City- toCity Cooperation (C2C). Sustainability 2019, 11, 5476; doi:10.3390/su11195476.

[11] Labrianidis, L., Ferrão. J., Hertzina, K., Kalantaridis, C., Piasecki, B., Sma- llbone, D. (2003). The Future fd Europe's rural periphery. Final Report. 5th Framework Programme of the European Community

[12] Sharpley, R., \& Vass, A. (2006). Tourism, Farming and Diversification: An Attitudinal Study, Tourism Management, 27, pp. 1040-1052.

[13] Grek, J., Karlsson, C., \& Klaesson, J. (2009). Market Potential and New Firm Formation. Working Paper Series in Economics and Institutions of Innovation 202. Royal Institute of Technology. CESIS - Centre of Excellence for Science and Innovation Studies.

[14] Castanho, R.A., Loures, L., Cabezas, J., and Garrido Velarde, J. (2020). The Socio-Cultural Factors in the Common Strategic Planning in European Territories: Principles for Sustainable Development Extracted from Borderlands. WSEAS
TRANSACTIONS on ENVIRONMENT and DEVELOPMENT, DOI: DOI: $10.37394 / 232015.2020 .16 .79$

[15] Castanho, R.A., Loures, L., Cabezas, J. \& Fernández-Pozo, L. (2016). Identifying critical factors for success in Cross Border Cooperation (CBC) development projects. Habitat International. doi.org/10.1016/j.habitatint.2016.10.004.

[16]UNWTO (United Nations World Tourism Organisation). (2008). International recommendations for tourism statistics. Madrid, Spain.

[17]Roy, S.C. \& Roy, M. (2015). Tourism in Bangladesh: Present status and future prospects. International Journal of Management Science and Business Administration, 1(8):53-61.

[18] van der Schyff, T. (2021). The development and testing of a measurement instrument for regional tourism competitiveness facilitating economic development. Doctoral Thesis. North-West University (NWU), South Africa.

[19] Karalkova, Y. (2016). Rural tourism destination competitiveness: Portugal vs. Belarus. Portugal: Polytechnic Institute of Bragança. (Dissertation- Masters).

[20] Phillip, S., Hunter, C. \& Blackstock, K. (2010). A typology for defining agritourism. Tourism management, 31(6):754-758.

[21] Sonnino, R. (2004). For a 'Piece of Bread'? Interpreting sustainable development through agritourism in Southern Tuscany. Sociologia Ruralis, 44(3):285-300.

[22] Barbieri, C. \& Mshenga, P.M. (2008). The role of the firm and owner characteristics on the performance of agritourism farms. Sociologia Ruralis, 48(2):166-183.

[23] Gordon, J.E. (2018). Geoheritage, geotourism and the cultural landscape: Enhancing the visitor experience and promoting geoconservation. Geosciences, 8(4):136-161.

[24] Mitchell, J. \& Li, S. (2017). Autonomy found: Estimating the local benefit from tourism in SIDS-the case of Cape Verde. Journal of Policy 
Research in Tourism, Leisure and Events, 9(2):182-200.

[25] Panfiluk, E. (2015). Impact of a tourist event of a regional range on the development of tourism. Social and Behavioural Sciences, 213:1020-1027.

[26] Smith, S.L. (2014). Tourism analysis: A handbook. 2nd ed. New York: Routledge.

[27] Andrades, L. \& Dimanche, F. 2017. Destination competitiveness and tourism development in Russia: Issues and challenges. Tourism Management, 62:360-376.

[28] Rizzi, P. \& Graziano, P. (2017). Regional perspective on global trends in tourism. Emerging Issues in Management, (3):11-26.

\section{Creative Commons Attribution License 4.0 (Attribution 4.0 International, CC BY 4.0)}

This article is published under the terms of the Creative Commons Attribution License 4.0 https://creativecommons.org/licenses/by/4.0/deed.en US 